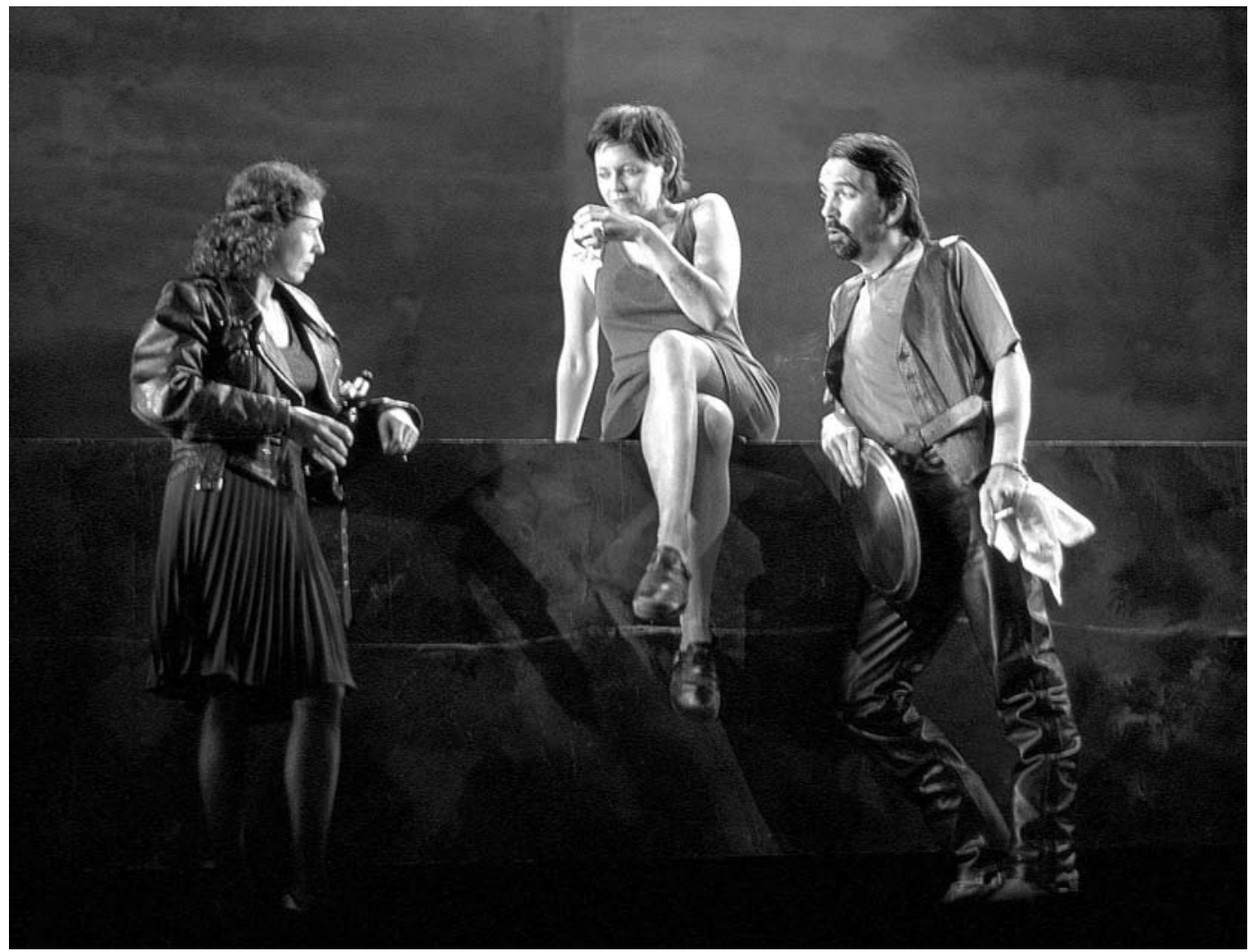

\title{
Ambições elevadas Nos cem anos do Abbey Theatre
}

\author{
Paulo Eduardo Carvalho
}

Nos primeiros cinco anos deste nosso século, terão sido pelo menos nove os dramaturgos irlandeses alvo da atenção dos mais diversos criadores teatrais portugueses: J.M. Synge, Brian Friel, Jennifer Johnston, Frank McGuinness, Marie Jones, Marina Carr, Conor McPherson, Martin McDonagh e Mark O'Rowe. A presença tão expressiva desta dramaturgia nos nossos palcos prolonga uma tendência já nítida durante os anos noventa do século passado, contrariando a sua chegada algo tardia a Portugal. Na verdade, em consequência dos muitos atrasos sistémicos do nosso teatro - em articulação directa com o relativo fechamento do país, as limitações impostas pela censura e as dificuldades várias que os criadores portugueses encontravam num qualquer esforço de renovação continuada dos repertórios, das práticas cénicas e dos hábitos e expectativas do público - só muito tardiamente é que a dramaturgia irlandesa chega até nós: Synge, nos anos 50 e 60, e 0'Casey, nos anos 70 e 80, serão os primeiros, mercê dos esforços de diversos tradutores, encenadores e divulgadores. Brian Friel é revelado ao público português em 1970, para só voltar a reaparecer na década de noventa.

Serve esta tão breve nota sobre a presença da dramaturgia irlandesa nos palcos portugueses para justificar a sinalização mais circunstanciada do centenário da instituição historicamente responsável pela aposta decisiva na criação de uma dramaturgia nacional, o Abbey Theatre. 0 dia 27 de Dezembro de 2004 registou, justamente, a passagem de cem anos sobre a inauguração de um novo teatro na Abbey Street, em Dublin, uma iniciativa da National Theatre Society, a "ficção" dramatúrgica e teatral que sucedia às experiências anteriores do Irish Literary Theatre e da Irish National Dramatic Company. Os fundadores do Irish Literary Theatre - Yeats, Lady Gregory e Edward Martyn - haviam-se proposto: "representar em Dublin na Primavera de todos os anos um certo número de peças celtas e irlandesas, as quais, seja qual for o seu grau de excelência, serão escritas com uma ambição elevada, de modo a construir uma escola celta e irlandesa de literatura dramática. Esperámos encontrar na Irlanda um público incorrupto e imaginativo, habituado a ouvir devido à sua paixão pela oratória... Mostraremos que a Irlanda não é uma nação de bufões ou de sentimentalismos piegas, tal como tem sido representada, mas a pátria de um idealismo de longa data. Acreditamos ter o apoio de todo o povo irlandês, cansado de ser incorrectamente representado, no desenvolvimento de uma obra que se pretende para lá de todas as questões politicas que nos dividem".

Mais do que identificar as múltiplas fantasias ou equívocos em que assentavam os propósitos enunciados, importará sublinhar a realidade que tão ambicioso desígnio acabaria por conformar. Se, por um lado, a sugestão de que haveria a necessidade de criar uma "escola irlandesa e celta de literatura dramática" rasurava por completo uma forte
Lady Gregory, Our Irish Theatre, New York \&t London, Putnam's Sons, 1913, p. 20. 
Riders to the Sea

Chun na Farraige Sios

de J.M. Synge,

enc. Conall Morrison,

Abbey Theatre, 2004

(Lucianne McEvoye

Caitriona Ni Mhurchu),

fot. Kip Carroll.

Shining City,

de Conor McPherson,

enc. Conor McPherson,

Royal Court, Londres,

e Gate Theatre, Dublin,

2004 (Michael McElhatton

e Kathy Kiera Clarke)

fot. Paul McCarthy.

${ }^{2}$ Robert Welch, The

Abbey Theatre 1899-

1999: Form and Pressure

Oxford, O.U.P. 1999;

Christopher Fitz-Simon

The Abbey Theatre:

Ireland's National Theatre.

The First 100 Years,

London, Thames $\&$

Hudson, 2003; Abbey On

Hundred: Book of Days,

Dublin, The Abbey

Theatre, 2003.

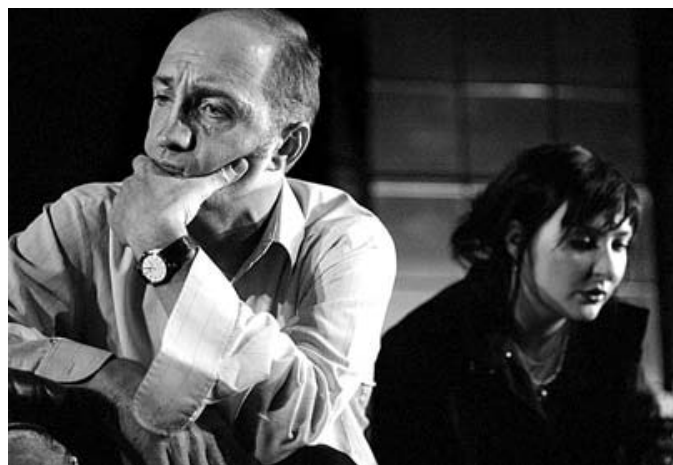

tradição dramática - anglo-irlandesa, é certo - que recuava até ao século XVII, por outro, essa era também uma estratégia para determinar os parâmetros em que se esperava ver avaliada a relação dessa nova dramaturgia com a história irlandesa. 0 público de que aqui se fala seria tudo menos "incorrupto", no sentido idealista que Ihe é atribuido, habituado como estava a frequentar os teatros mais populares de Dublin, onde com regularidade se oferecia, entre outros divertimentos, uma dieta de melodrama nacionalista. Quanto à indiferença ou exterioridade deste projecto relativamente às divisões políticas que atravessavam então a sociedade irlandesa - e às quais os protestantes anglo-irlandeses seriam singularmente sensiveis - acabariam por ser os próprios factos a demonstrar que terá sido justamente por este projecto de um teatro nacional se colocar no centro do debate político que a sua sobrevivência terá sido tão notavelmente assegurada. De forma quase única na Europa de então, o Abbey Theatre passa a receber um subsídio do Estado irlandês a partir de 1925, mercê não só dos esforços de Yeats, mas também das credenciais nacionalistas entretanto adquiridas por aquele teatro.

Embora o lançamento e a afirmação deste Teatro Nacional irlandês se tenha ficado a dever à determinação inspirada de alguns criadores, como aqueles já referidos a que se deveria acrescentar o nome de Synge - será importante não esquecer a coincidência de um conjunto acrescido de forças, nos terrenos ideológico, político, social, cultural e especificamente teatral, para melhor compreendermos as razões da implantação nacional de um projecto tão audacioso como precário e a extraordinária projecção internacional do trabalho ali produzido. Se é verdade que o Abbey Theatre foi, e continuaria a ser, uma fantasia de escritores - e talvez esta fosse a mais "elevada" das suas "ambições" -, não será menos correcto reconhecer a circunstância de tais propostas de novas, e muitas vezes controversas, representações da nação terem encontrado formas igualmente novas de representação teatral. Porque foi também no encontro regular de novos actores e na experiência arriscada de novos métodos de interpretação,

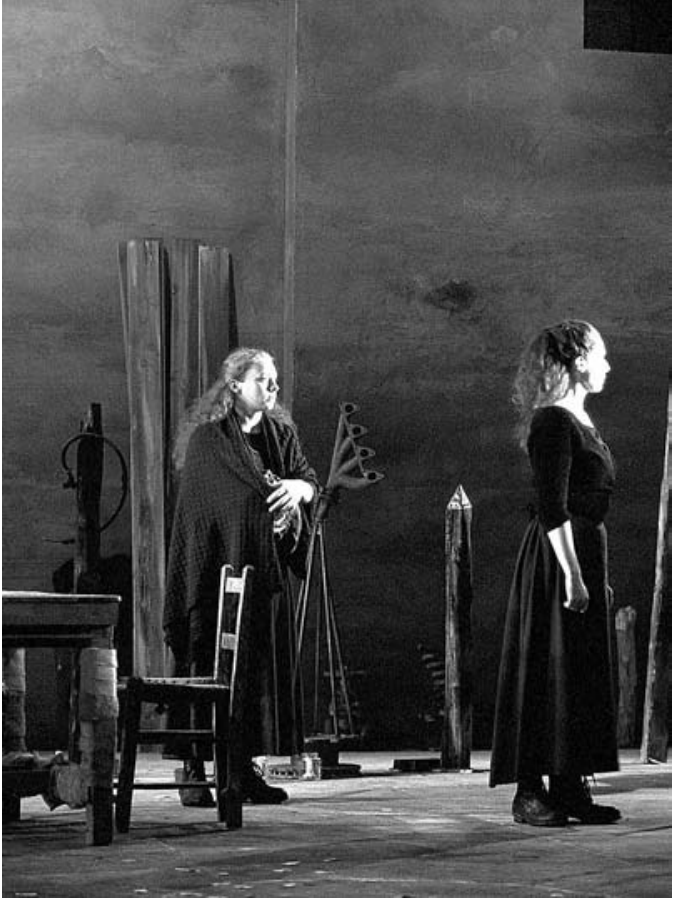

servidos por soluções cenográficas capazes de oscilar entre o delírio mais pictórico e o mais surpreendente despojamento das convenções naturalistas, que o Abbey acabaria por se impor como uma "companhia", o que era então realidade quase inédita em contexto cultural anglófono e colocava a Irlanda a par das movimentações teatrais que se ensaiavam em contexto europeu continental.

Seria um grave erro histórico sugerir que os últimos cem anos de teatro irlandês são redutiveis à actividade do Abbey Theatre. Contudo, a centralidade daquele Teatro Nacional na produção dramática irlandesa impõe-se como um facto incontestável: 742 novas peças produzidas em 100 anos é um número assaz eloquente e dificilmente ultrapassável por qualquer outra instituição criada em bases semelhantes. A importância histórica desta instituição teatral surge claramente sublinhada pelo número e qualidade de alguns dos estudos recentemente publicados que a tomam como objecto central de atenção. ${ }^{2}$

As diversas iniciativas programadas pelo Abbey Theatre para a celebração dos seus cem anos foram acompanhadas do mesmo tipo de agitação, polémica e discussão que marcaram muitos dos momentos da sua história centenária. O programa anual surgiu com a designação genérica de "abbeyonehundred" (Abbey cem) - divulgado desde o final de 2003 através de um programa de quase cem páginas abundantemente ilustrado -, e organizou-se em torno de cinco temas: "O Abbey e a Europa", "O Abbey e a Nova Escrita", "O Verão no Abbey", "0 Abbey e a Irlanda" e "0 Abbey em digressão". Em digressão pela Irlanda, pelos Estados Unidos ou pela Austrália andaram três produções recentes de The Playboy of the Western World (1907) / 0 valentão do mundo ocidental, de The Plough and the Stars (1926) / O arado e as estrelas, de Sean O'Casey, e de The Gigli Concert (1983) / O concerto de Gigli, de Tom Murphy, todas elas encenadas por Ben Barnes, o director do Abbey desde 2000, a que se juntou ainda The Shaughraun, um melodrama nacionalista da segunda metade do século XIX, de Dion Boucicault, algo polemicamente encenado pelo criador de Riverdance, John McColgan. 0 programa 


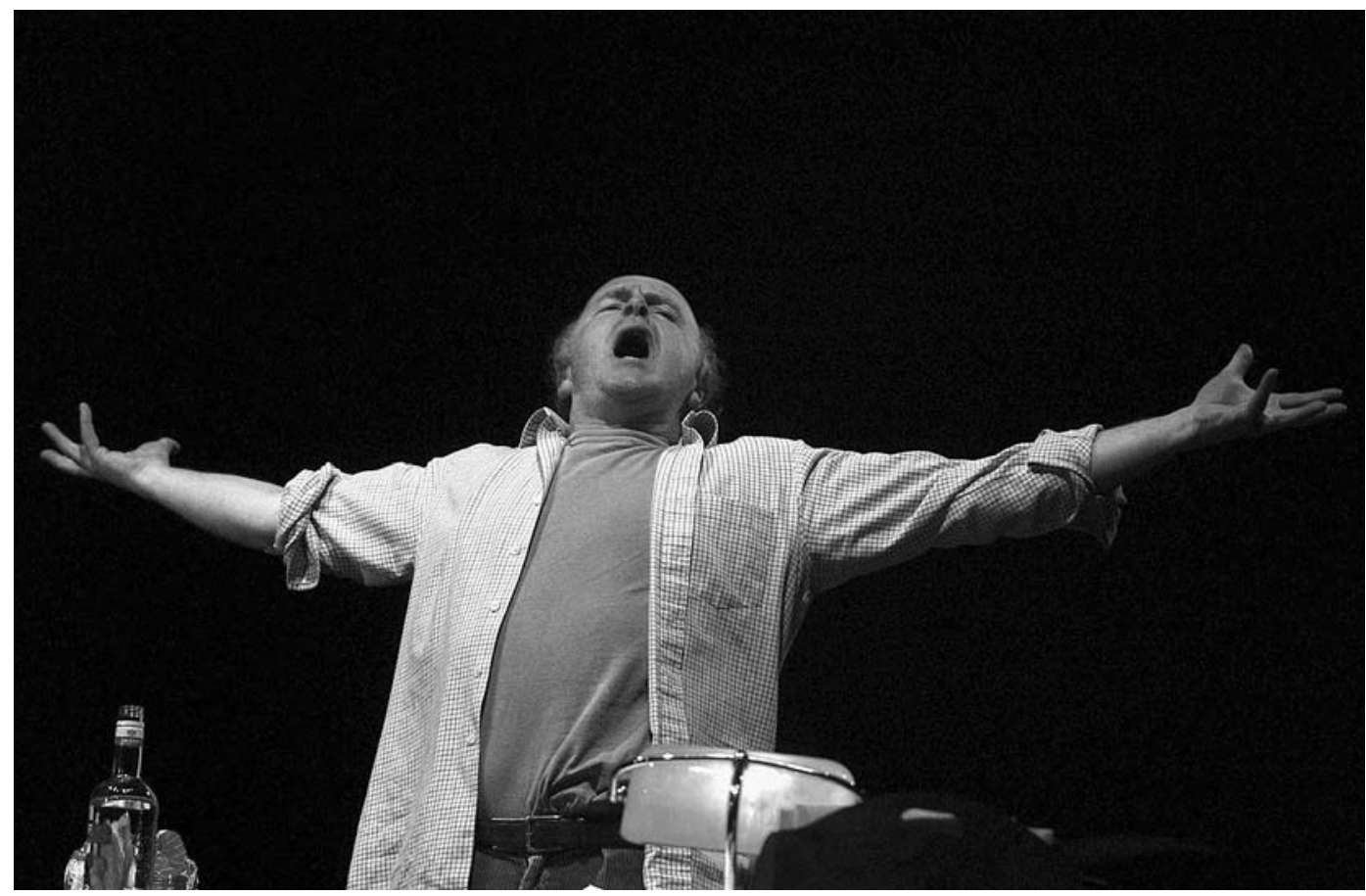

de "O Abbey e a Europa", claramente empenhado no reforço dos laços que desde o início ligaram a dramaturgia irlandesa a modelos e paradigmas dramatúrgicos do continente europeu, incluiu duas novas versões de textos clássicos, 0 cerejal, de Tchekov, e Antígona, de Sófocles, assinadas respectivamente por Tom Murphy e pelo poeta nobelizado Seamus Heaney (neste último caso, sob um outro título, The Burial at Thebes / 0 funeral em Tebas).

A principal motivação de "O Abbey e a nova escrita" terá sido a de contribuir para o aparecimento de novos textos, de autores consagrados e de outros mais jovens, mas resultou talvez no programa mais contestado, limitado a cinco propostas, de resultados muito diversos, da autoria de Paula Meehan, Peter Sheridan, Stuart Corolan, Eugene O'Brien e Paul Mercier. A estas poderíamos ainda acrescentar Beauty in a Broken Place / Beleza num lugar destruido, a primeira peça do romancista e ensaísta Colm Tóibin, apostada na recuperação dos protagonistas dos acontecimentos que rodearam a tumultuosa estreia de The Plough and the Stars, de O'Casey, em 1926, revisitando assim a discussão sobre a liberdade cultural, política e artística do então jovem estado irlandês independente, confrontado com uma visão muito crítica dos acontecimentos ligados à Insurreição da Páscoa de 1916. A peça de Tóibin integrou a programação de "O Verão no Abbey", juntamente com as já referidas produções de The Shaughraun e de The Playboy of the Western World e ainda de Heavenly Bodies (1986) / Corpos celestiais, do já desaparecido Stewart Parker, encenado por Lynner Parker.

"O Abbey e a Irlanda" foi a designação ambiciosa escolhida pela direcção daquele Teatro para recobrir o conjunto de dezoito peças apresentadas durante os catorze dias de duração do Festival de Teatro de Dublin, entre 27 de Setembro e 9 de Outubro de 2004. Esclareça-se que onze daquelas peças foram simplesmente objecto de uma leitura pública, ainda que acompanhada de uma apresentação crítica pelos mais diversos investigadores do teatro irlandês, em sessões realizada na acanhada sala de ensaios do Abbey, no âmbito de uma iniciativa que recebeu o título "Lendo as décadas" e que contemplou textos de Lady Gregory, G.B. Shaw, T.C. Murray, Denis Johnston, George Shields, M.J. Molloy, Walter Macken, Thomas Kilroy, Tom MacIntyre, Sebastian Barry e Brian Friel. A selecção das outras sete peças terá resultado mais de opções condicionadas pela própria lógica repertorial praticada pela actual direç̧ão do Abbey do que de uma escolha criteriosa de objectos dramatúrgicos representativos de um século de escrita. Ainda assim, esta foi uma oportunidade rara para o público, que acompanhou aquele festival, de se confrontar com um conjunto de peças tão diversamente expressivas da riqueza da dramaturgia irlandesa, divididas entre a sala grande do Abbey e a sua sala mais pequena, o Peacock Theatre.

Tirando partido da imensa variedade de peças em um acto escritas pelos mais diversos dramaturgos irlandeses, o encenador Connal Morrison reuniu três peças numa só noite: uma quase obscura e surrealista fantasia de George Fitzmaurice, The Dandy Dolls / As bonecas especiais, rejeitada em 1913 por Yeats e Lady Gregory, e só estreada em 1945; Purgatory (1938) / Purgatório, um dos mais belos e perturbadores textos dramáticos escritos por Yeats, proposta de revisitação da violência associada à história política irlandesa, através da história de um pai que assassina o seu filho; e Riders to the Sea (1904) / Cavalgada para o mar, a tragédia das gentes que dependem do mar, de Synge - que tanto terá impressionado o nosso Fernando Pessoa -, representada em gaélico, neste espectáculo, com o título Chun na Farraige Síos.

Martin Drury encenou I Do Not Like Thee Doctor Fell | Eu não gosto de si, Doutor Fell, uma engenhosa comédia de Bernard Farrell, estreada em 1979. Esta sátira divertida, mas assaz anódina, aos grupos de tratamento, muito populares nos Estados Unidos naquela década, apresentouse como uma escolha bizarra, prejudicada pela inclemente passagem do tempo sobre a topicalidade de uma ficção mais devedora das estratégias de um Alan Ayckbourn do que de uma qualquer tradição mais interpeladora da realidade irlandesa. 
Ben Barnes recuperou para esta mostra a sua encenação segura de The Gigli Concert que em 2001 integrara a homenagem do Abbey àquele dramaturgo, por ocasião dos seus 70 anos. Murphy é, com Friel, um dos maiores dramaturgos irlandeses das últimas quatro décadas do século XX, e The Gigli Concert, estreado naquele Teatro, em 1983, um dos mais extraordinários textos do nosso tempo: trata-se de uma interrogação em profundidade dos condicionamentos da identidade individual e colectiva, baseada numa subtil reescrita do mito fáustico, protagonizada por dois "anjos caídos", o "dinamatologista" J.P.W. King e um anónimo Homem Irlandês, dois sobreviventes apoiados em ilusões, com uma desesperada necessidade de redenção, de religação, de uma qualquer forma de transcendência.

Observe the Sons of Ulster Marching Towards the Somme (1985) / Os filhos do Ulster marchando em direcção ao Somme, de Frank McGuinness, baseia-se num episódio particularmente marcante da Primeira Guerra Mundial, a sangrenta Batalha do Somme, para se atrever a explorar o imaginário político e cultural dos protestantes da Irlanda do Norte, com uma extraordinária ousadia formal e uma sensibilidade lírica rara que 0 encenador Robin Lefevre parece ter querido respeitar.

De Marina Carr, a única dramaturga incluida neste grupo de sete textos, o Abbey apresentou Portia Coughlan, de 1996, com encenação de Brian Brady, um mergulho tão fascinante como perturbador na história de uma outra personagem com uma identidade irremediavelmente estilhaçada, Portia (em distorcido eco shakespeariano), numa ficção que tenta destemidamente cruzar uma estrutura realista com o lirismo e a caricatura possibilitados pelas estratégias expressionistas, intensamente problematizadora do inferno familiar e dos papéis sociais de filha, esposa e mãe.

Para lá desta generosa programação do Abbey, o Festival de Teatro de Dublin incluia ainda mais teatro irlandês: duas peças de Synge, The Tinker's Wedding (1909) / O casamento do latoeiro, e The Well of the Saints (1905) / O poço dos santos, encenadas de forma decepcionante por Gary Hynes para a Druid Theatre Company, de Galway - a mais respeitada companhia de teatro irlandesa, criada nos anos 70, responsável pela criação e revisitação de muitos textos dramáticos irlandeses - e Shining City / Cidade brilhante, a mais recente peça de Conor McPherson, igualmente responsável pela encenação, numa co-produção do Royal Court, de Londres, onde o espectáculo estreou, em Junho de 2004, e do Gate Theatre, de Dublin. Grande "rival" do Abbey, o Gate foi fundado em 1928 por Hilton Edwards e Mícheál Mac Liammóir e encontra-se, desde 1983, nas mãos hábeis e experimentadas de Michael Colgan. Shining City estabelece um diálogo interessante, mas ingrato, com The Gigli Concert, de Tom Murphy, revelando, contudo, uma vez mais os dotes narrativos de McPherson, o seu indiscutivel talento para a partilha de histórias

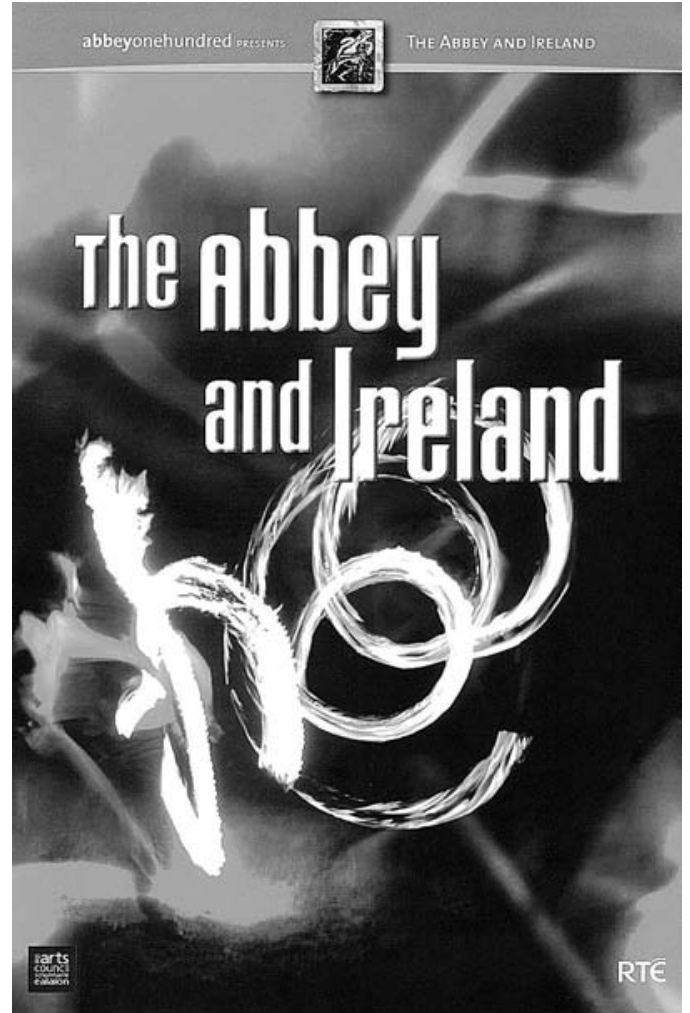

capazes de prender o espectador num jogo de intimidade e de fascínio.

Embora esta listagem pretenda funcionar como demonstração eloquente da renovada vitalidade da dramaturgia irlandesa, será preciso acrescentar que para este espectador se vem repetindo a desagradável constatação de uma prática teatral paradoxalmente incapaz de responder aos mais interessantes desafios oferecidos por um tão variado e ousado repertório.

Refiro-me a uma espécie de rotina, sem dúvida profissional e algumas vezes talentosa, mas que não mostra vontade de encontrar as necessárias estratégias de representação e de figuração cénica capazes de arrancar alguns daqueles textos do peso de uma tradição dominantemente realista, excessivamente presa às tábuas do palco e muito resistente ao fôlego lírico de tantas daquelas ficções. Como sugeria o critico de teatro Fintan O'Toole, no debate público promovido pelo Irish Theatre Magazine, num dos últimos dias do festival, é como se a dramaturgia irlandesa, embora de forma hesitante, tivesse continuado a explorar os desafios dramatúrgicos tão corajosamente lançados nas primeiras décadas do século XX por Yeats, Synge e O'Casey, enquanto que a criação teatral se acomodou numa espécie de artesania cénica e numa rotina interpretativa, negando ao teatro o reconhecimento da sua indispensável autonomia artística. Algo que faltou a este festival, e ao conjunto de celebrações programadas pelo Abbey, foi justamente o confronto com algumas das encenações que por essa Europa, e pelo mundo - desde que dele se exclua a Grã-Bretanha e os Estados Unidos... -, se vão fazendo dos textos dramáticos irlandeses, com um outro entendimento da criação teatral, das linguagens cénicas e da "liberdade para experimentar" de que, com uma ambição não menos elevada, falava o próprio Yeats. 